\title{
O Padrão das O ndas de Verão e O utono no Litoral Sul e Norte do Rio Grande do Sul
}

\author{
João Carlos Strauch, Debora Copstein Cuchiara \\ Universidade Federal do Rio Grande \\ strauch@vetorial.net; dmtdc@furg.br \\ Elírio Ernestino Toldo Júnior \\ Centro de Estudos de G eologia Costéra e 0 ceânica, CECO-IG -UFRGS \\ toldo@.ufrgs.br \\ Luiz Emílio Sá Brito de Almeida \\ Institu to de Pesquisas H idráulicas, IPH -UFRGS \\ luiz.almeida@ufrgs.br
}

Recebido: 02/ 10/07 - revisado: 29/ 10/07 - aceito: 04/ 12/09

RESUM 0

Com o objetivo de realizar uma comparação do campo de ondas oceânicas en tre o litoral sul e norte do Rio Grande do Sul foram analisadas séries de dados adquiridos com ondógrafo direcional waverider da Datawell, fundeado em outubro de 1996 nas proximidades da desembocadura da Lagoa dos Patos, em Rio Grande, e em novembro de 2006 na praia de Tramandaí, ambos na profundidade de $17 \mathrm{~m}$. N este trabalho são apresentados os dados medidos envolven do altura significativa, período significativo, en ergia e direção de pico das on das registradas. 0 s resultados in dicam u ma grande semelhança entre o comportamen to do regime on du latório de outono e de verão para estas duas localidades. As alturas significativas no verão em Tramandaí e Rio Grande se distribuíram com valores proporcionais en tre 1,5 e 3,0 m de ESE a SSE, com predominância para a direção de SE em Tramandaí e SSE em Rio Grande. No outono em Tramandaí, os resultados indicaram alturas significativas com predominância para a direção de SSE, atingin do as maiores freqü ên cias os valores en tre 1,0 e2,0 m. Em Rio Grande as alturas significativas ocorrem no quadrante $S E$, atingindo valores máximos de 5,0 m com um progressivo aumento de freqüência da direção E para SSE.

Palavras-chave: Ondas oceânicas; padrão das on das.

\section{INTRODUÇÃO}

O estado do Rio Grande do Sul tem uma extensa costa com orientação uniforme NE-SW e leve sinuosidade ao longo dos seus $630 \mathrm{~km}$ (Fig. 1). Toda esta extensão é constituída por depósitos quaternários inconsolidados que não recebem contribuições de areias modernas, pois toda carga de tração transportada pela rede de drenagem interior é retida nas lagunas e outros ambientes costeiros, como por exemplo, a Lagoa dos Patos e a Lagoa Mirim. A Plataforma Continental é parte de uma ampla e passiva margem, com mais de $150 \mathrm{~km}$ de extensão, profundidades máximas variando entre 100 e $140 \mathrm{~m}$ e suave declividade da ordem de $0,06^{\circ}$. A antepraia é extensa e rasa com limite externo na profundidade de $10 \mathrm{~m}$, onde predominam depósitos arenosos (Toldo et al., 2006).

Os efeitos resultantes das ondas superficiais têm importância fundamental para a gestão costeira, pois se trata da principal forçante na dinâmica, morfologia e composição da linha de costa do estado (Tomazelli e Villwock, 1992).

Grande parte da energia incidente neste tipo de zona costeira está associada às ondas de gravidade, as quais são usualmente investigadas de dois modos principais. 0 primeiro diz respeito ao clima de ondas e sua variação sazonal. 0 segundo inclui a física do campo de ondas dos oceanos. Estudos de clima de ondas são mais importantes devido a suas aplicações práticas aos projetos de engenharia, a segurança da navegação e ao gerenciamento costeiro. 
O clima de ondas corresponde ao padrão estatístico dos seus parâmetros descritivos, tais como a altura, período, direção de propagação e energia. As ondas geradas pelo vento local são aqui designadas por vagas ou sea, e aquelas geradas por tempestades longe do local de geração por ondulações ou swell. Em geral, no litoral do Rio Grande do Sul, os dois regimes estão presentes, o que caracteriza um espectro direcional bi-modal, interferindo um sobre o outro e com predominância ora das vagas, ora das ondulações (Wainer, 1963). Para a costa sul do Brasil, a chegada de ondulações está associada a um centro de geração de tempestades extra-tropicais que se localiza em geral ao largo, no sul da Argentina. Exceto pela passagem das frentes frias de S e SE, a agitação marítima é caracterizada por ondas de média a elevada energia, com altura significativa da ordem de $1,5 \mathrm{~m}$ e período entre 7 e $9 \mathrm{~s}$ (Almeida et al., 1997, 1999).

De acordo com a classificação dinâmica global de costas, proposta por King (1972), o litoral do Rio Grande do Sul se apresenta como uma "Costa de O ndulações de Leste". Esses ambientes ocupam as baixas latitudes entre os cinturões de ondulações de tempestades. As ondulações são construtivas, longas e de pequena esbeltez.

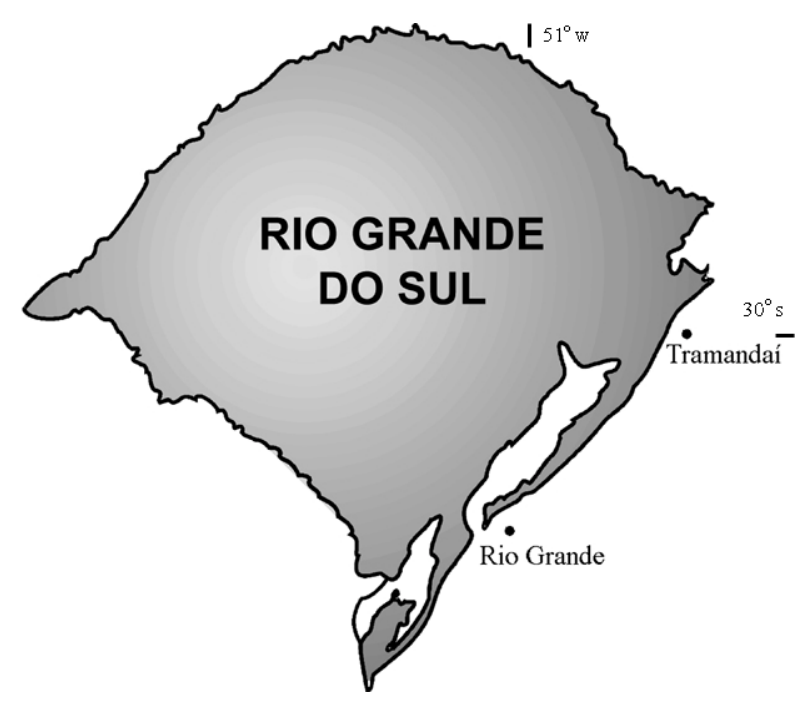

Figura 1 - Localização dos fundeios dos ondógrados no litoral do RS, em Tramandaí e Rio Grande.

A maré astronômica é semi-diurna, com amplitude média de $0,25 \mathrm{~m}$, sendo que a maré meteorológica pode alcançar 1,20 m (Almeida et al., 1997). A profundidade de fechamento é estimada em 7,5 m, calculada com base em dois conjuntos de dados de ondas coletados nos anos de 1963 e 1996 no Litoral Norte do estado (Almeida et al., 1999).

Pretende-se neste trabalho apresentar os resultados de um recente monitoramento de ondas na praia de Tramandaí (Figura 1), Litoral Norte do RS, e comparar com dois estudos já realizados. 0 primeiro é o de Wainer (1963), também em Tramandaí, e o segundo é de Strauch (2001), na cidade de Rio Grande.

\section{REVISÃO BIBLIOGRÁFICA}

Poucos pesquisadores desenvolvem o monitoramento do clima de ondas utilizando ondógrafos. 0 motivo é $o$ alto custo do equipamento e 0 enorme risco de acidentes, dentre estes se ressalta o rompimento de sua amarração ao fundo do oceano. Outro problema recorrente é a falha de transmissão dos dados do ondógrafo ao receptor em terra, principalmente quando instalados a grandes distâncias, com transmissão por ondas de rádio.

Para que o monitoramento das ondas tenha sucesso é necessário uma continuidade dos registros. O conhecimento do clima ondulatório implica em longas campanhas de campo, para que se estabeleçam considerações válidas. Infelizmente estes casos são raros na costa brasileira e o comum é se aproveitar pequenos intervalos de monitoramentos e extrapolar os resultados para utilização em casos específicos. É o que fez Wainer (1963), que a partir de 9 meses de informações do regime de ondas em Tramandaí, determinou a previsão da onda significativa e da onda máxima de projeto para tempos de retorno de 30 e 100 anos. Machado e Strauch (2001), analisaram estes dados com aqueles adquiridos em 3 anos de monitoramento em Rio Grande, encontrando para duas distribuições estatísticas de extremos, valores com aproximadamente $20 \%$ de diferença àqueles propostos por Wainer (1963).

Almeida e Toldo (1997), durante a execução do projeto "Estudos Ambientais em Áreas Costeiras e O ceânicas", realizado através de convênio entre a Petrobrás e Universidades da região sul do Brasil, fundearam um ondógrafo direcional waverider da Datawell, na praia de Tramandaí no local de coordenadas 30 $000^{\prime} \mathrm{S}$ e $50^{\circ} 06^{\prime} \mathrm{W}$ na profundidade de $19 \mathrm{~m}$, nas proximidades da monobóia 01 (Figura 1). O s dados de ondas foram adquiridos entre fevereiro e outubro de 1996. Devido a problemas operacionais houve fal has nos registros, mas identificou-se uma altura significativa média das ondas de 1,44 m e 
um período significativo médio de $8,3 \mathrm{~s}$, conforme figuras 2 e 3.

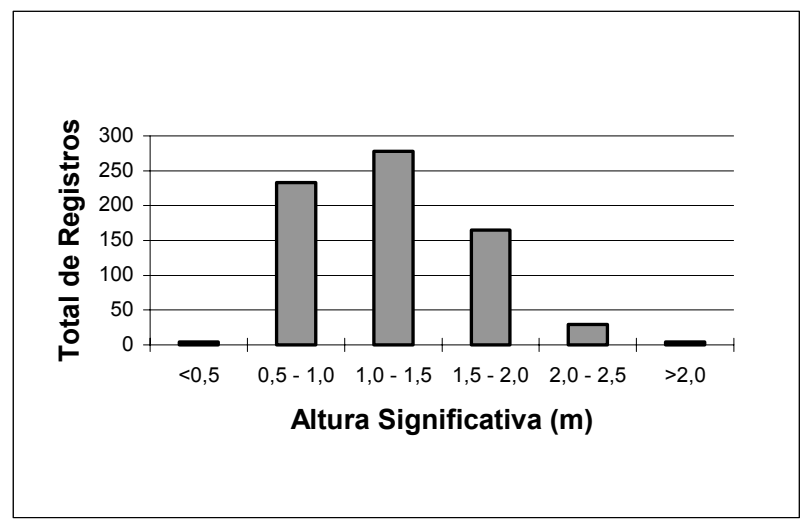

Figura 2 -Distribuição de alturas significativas em Tramandaí (Almeida e Toldo, 1997).

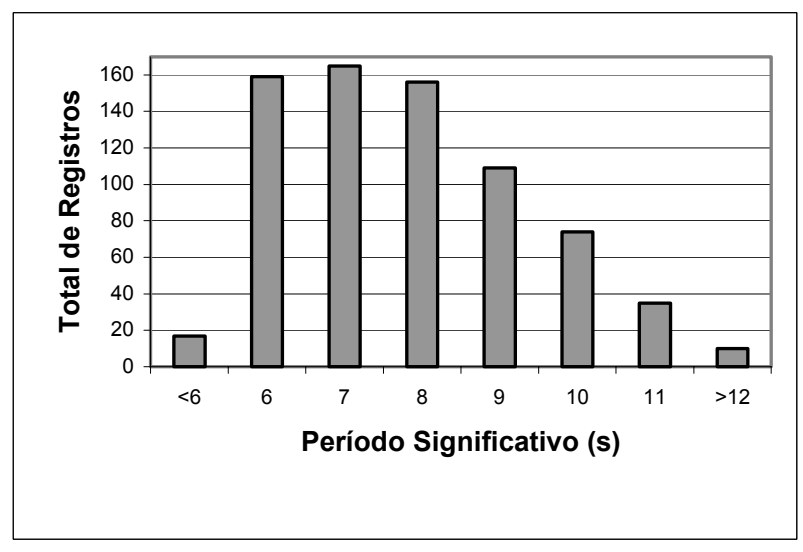

Figura 3 -Distribuição de períodos significativos em Tramandaí (Almeida e Toldo, 1997).

$\mathrm{Na}$ década de 60 a Petrobrás solicitou ao Instituto de Pesquisas Hidráulicas - IPH (Wainer, 1963), a determinação da onda máxima na região de Tramandaí tendo como base uma campanha de campo realizada entre outubro de 1962 e setembro de 1963. 0 aparelho utilizado foi um ondógrafo tipo "Houlographe". Dois registros diários foram programados com duração de 15 e 12 minutos, respectivamente. Em paralelo era feita uma observação visual, em uma plataforma erguida junto à costa, da direção de aproximação das ondas.

0 ondógrafo foi fundeado a uma profundidade de $18 \mathrm{~m}$. A impossibilidade de manutenção do mesmo gerou diversas descontinuidades no registro, com um aproveitamento de aproximadamente $46 \%$ do tempo programado de monitoramento, destacando-se a ocorrência de ondas excepcionais de $7 \mathrm{~m}$ de altura. A seguir são apresentadas as principais considerações e conclusões deste estudo:

1) Em Tramandaí ocorrem vagas e ondulações cuja altura significativa de maior freqüência é de $1,50 \mathrm{~m}$, para $23 \%$ do ano. Alturas significativas superiores a $2 \mathrm{~m}$ ocorrem em $16 \%$ dos dias do ano (Figura 4).

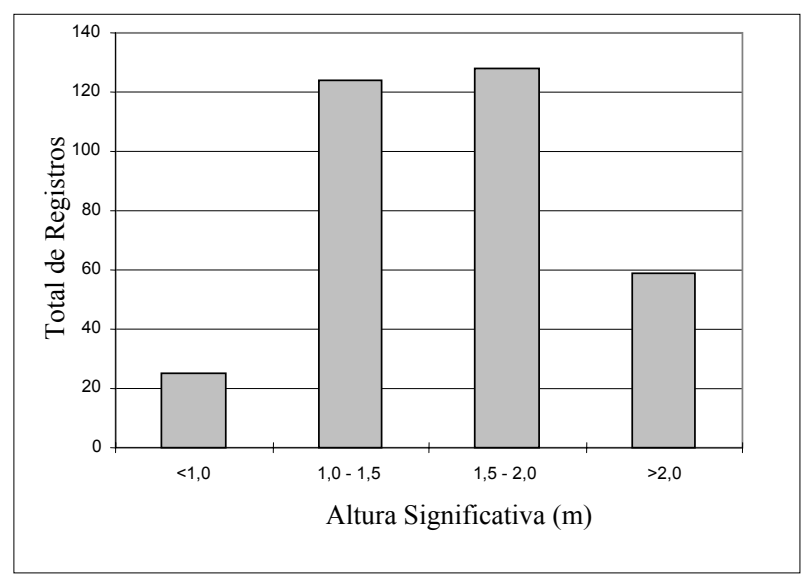

Figura 4 - Distribuição das alturas significativas em Tramandaí entre 1962 e 1963 (Wainer, 1963).

2) O período significativo de maior freqüência é de $8 \mathrm{~s}$, ocorrendo uma distribuição normal desde os 5 s até um máximo absoluto de $17 \mathrm{~s}$, registrado durante a ressaca de abril de 1963 ( Figura 5).

3) As direções de aproximação das ondas se deram praticamente perpendicular à linha de praia, por se apresentarem refratadas para o local de observação. A correlação gráfica entre as direções de aproximação das ondas e o índice energético das mesmas, $\mathrm{H}_{\mathrm{s}}{ }^{2}$ $L_{s}$ (onde $H_{s}$ é a altura significatica e $L_{s}$ é 0 comprimento de onda significativa), indica uma resultante para a direção LesteSudeste. 


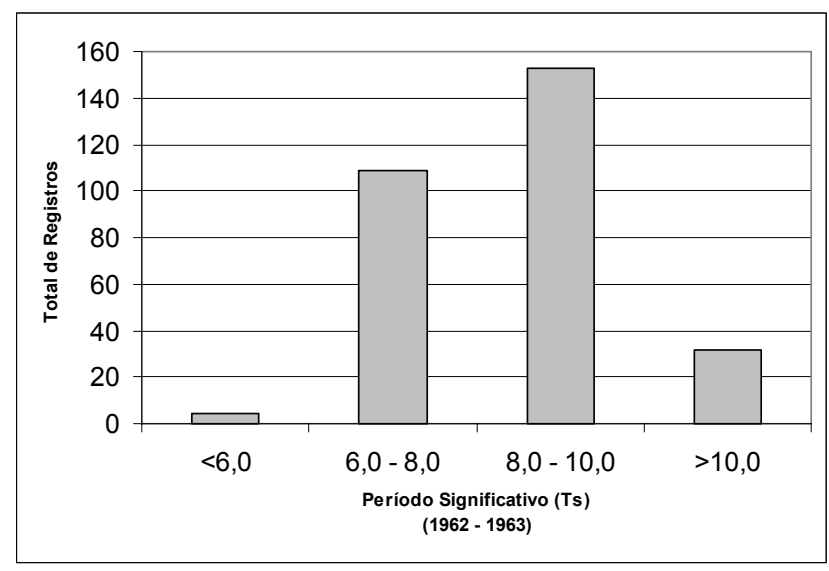

Figura 5 - Distribuição de períodos significativos em Tramandaí entre 1962 e 1963 (Wainer, 1963).

4) Os ventos predominantes em Tramandaí são de Nordeste enquanto que apenas $24 \%$ das ondas têm direção Leste-Nordeste, 0 que leva a concluir que, de uma maneira geral, neste trecho da costa as ondas não têm a mesma direção de aproximação do vento.

5) As alturas de ondas que ocorrem em Tramandaí não apresentam variações sazonais, e assim não há diferenciação notável entre os registros de ondas em dezembro (verão) e agosto (inverno), por exemplo.

Em Rio Grande o monitoramento do clima ondulatório foi realizado nas proximidades da desembocadura da Lagoa dos Patos (Figura 1), a partir de outubro de 1996, com o fundeio do ondógrafo direcional, tipo waverider, nas coordenadas $32^{\circ} 10^{\prime} \mathrm{S}$ e $51^{\circ} 58^{\prime} \mathrm{W}$.

A pesquisa teve início através de uma parceria entre a Fundação Universidade do Rio Grande FURG, e o Instituto de Pesquisas Hidroviárias - IN$\mathrm{PH}$, com o objetivo de subsidiar o projeto de recuperação do molhe leste da barra. As operações de fundeio foram realizadas com o auxílio de embarcações da Marinha do Brasil, na profundidade de 17 $\mathrm{m}$.

Estudos anteriores (Strauch, 1997), dizem respeito ao levantamento do clima ondulatório através de um antigo ondógrafo não direcional, também do tipo waverider, localizado nas proximidades do canal de acesso ao porto. Durante aproximadamente dois meses foram adquiridos dados de altura e período das ondas em um receptor analógico. 0 projeto foi viabilizado através de convênio firmado entre a FURG e o Centro de Desenvolvimento da Tecnologia Nuclear - CDTN. Integrou-se ao projeto a Universidade do Vale do Itajaí —UNIVALI, com a instalação de um ondógrafo similar na praia de Camburiú, SC.

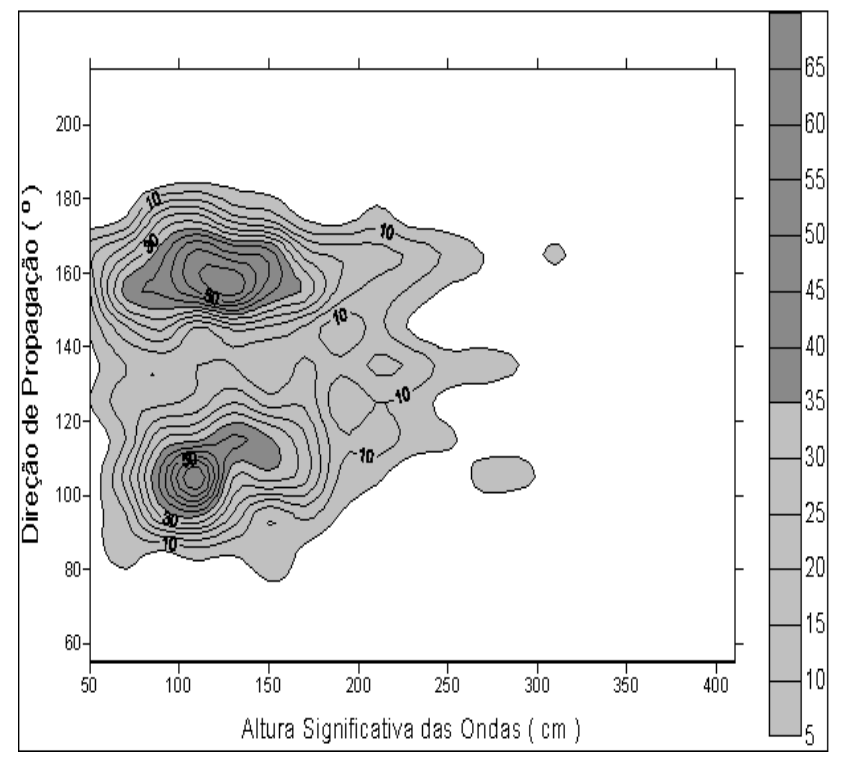

Figura 6 - Diagrama de freqüência absoluta entre altura significativa e direção de propagação das ondas em Rio Grande (Strauch, 2001).

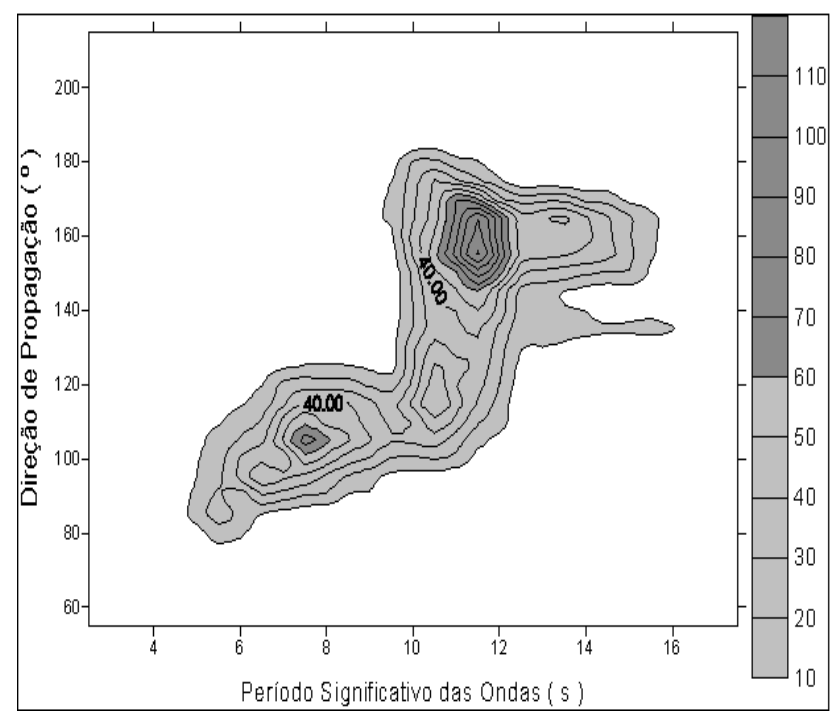

Figura 7 - Diagrama de freqüência absoluta entre período significativo e direção de propagação das ondas em Rio Grande (Strauch, 2001). 
Dentre os trabalhos realizados a partir dos registros obtidos, destaca-se a análise do clima de ondas para 28 meses contínuos de registros. Parâmetros descritivos básicos da onda, como altura significativa, período significativo e de pico, energia de pico e direção de propagação das ondas foram selecionados e representados em diagramas, com o objetivo de comparação para determinar qual o padrão das ondas no litoral do Rio Grande do Sul. Os diagramas de freqüência apresentados nas figuras 6 e 7, mostram os dois regimes de ondas incidentes.

As principais considerações e conclusões deste monitoramento são apresentadas a seguir:

1) Na figura 6 é revelado as duas direções típicas de propagação das ondas, na posição do ondógrafo, ou seja, ondas com altura significativa média de $1 \mathrm{~m}$ propagando-se com uma direção média de $110^{\circ}$ (ESE), e ondas com altura significativa média de $1,50 \mathrm{~m}$ propagando-se com uma direção média de 160 o (SSE).

2) Na figura 7 é mostrado a predominância de ocorrência dos dois regimes citados, ou seja: as ondas locais ou sea com período significativo médio de $8 \mathrm{~s}$, e as ondas de fora ou swell com período significativo médio de $12 \mathrm{~s}$.

3) O diagrama polar da figura 8 mostra que a direção de propagação de ondas mais freqüente nesta região corresponde ao quadrante SE.

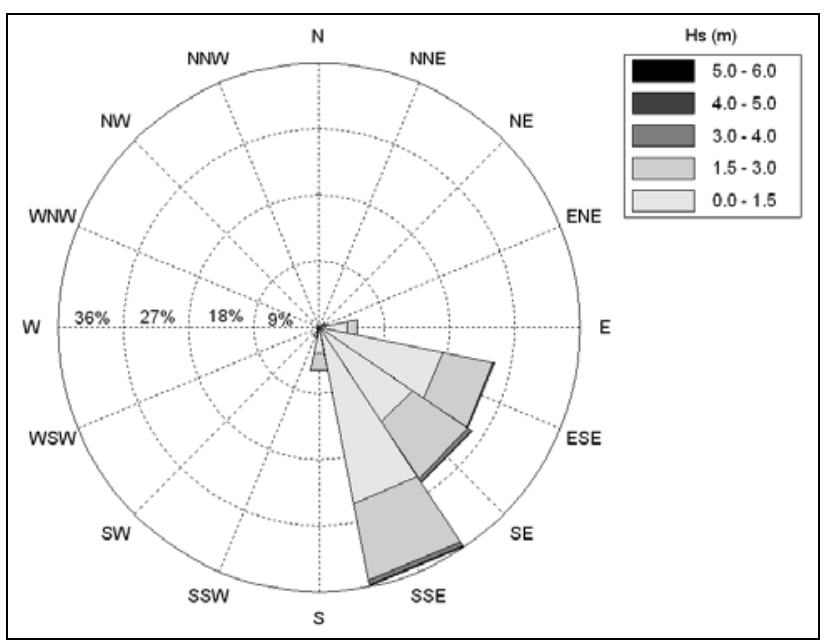

Figura 8 - Rosa de ondas de freqüência relativa da distribuição direcional da altura de significativa das ondas para todo o período monitorado (Strauch, 2001).
4) Em geral os dois regimes de ondas estão presentes em todas as estações do ano, com uma predominância da direção SSE, com exceção da primavera quando a distribuição da direção é praticamente uniforme em todo o quadrante.

5) O s eventos mais energéticos ocorrem durante 0 outono, com a chegada de ondas longas do tipo swell, provenientes de tempestades extratropicais, cujo foco de geração é no extremo sul do continente, seguindo-se 0 inverno.

6) Não há diferenças significativas entre o clima de ondas de outono e o de inverno. 0 mesmo pode ser dito para o de verão e primavera, com exceção na direção de propagação de ondas que se mostra mais de leste na primavera.

7) As maiores alturas significativas de ondas ocorrem no outono, com uma altura máxima registrada de $8,5 \mathrm{~m}$.

\section{MONITORAMENTO DE ONDAS EM TRAMANDAÍ E RIO GRANDE.}

Com a finalidade de se obter uma série Ionga e contínua de dados de ondas para a região de Tramandaí (Figura 1), foi realizado o fundeio do ondógrafo direcional waverider da Datawell, em novembro de 2006, em uma parceria entre a Petrobrás/ Transpetro e a Universidade Federal do Rio Grande do Sul. A instalação do equipamento foi realizada nas proximidades da monobóia 01 , a uma profundidade de $17 \mathrm{~m}$.

Os arquivos de dados brutos foram adquiridos para constituição do banco de dados. Destes, foram selecionados para efeito comparativo os resultados da altura significativa, período de pico, energia de pico e a direção de propagação de pico para o verão e o outono no Litoral Sul e Norte do Rio Grande do Sul, os quais estão apresentados em diagramas polares nas figuras 9 a 14. Os dados do Litoral Sul foram adquiridos em Rio Grande (Strauch, 2001), e foram comparados com aqueles do Litoral Norte.

Os resultados indicam uma grande semeIhança entre o comportamento do clima de ondas de outono e de verão para Rio Grande e Tramandaí (Strauch et al., 2007).

As alturas significativas no verão em Tramandaí se distribuíram entre as direções de ENE e $\mathrm{S}$ 
com valores proporcionalmente divididos até $1,5 \mathrm{e}$ 3,0 $\mathrm{m}$ de ESE a SSE com predominância para a direção de SE (Figura 9A). Em Rio Grande, os dados se distribuíram uniformemente nas mesmas direções, com predominância para a direção de SSE (Figura $10 \mathrm{~A})$.

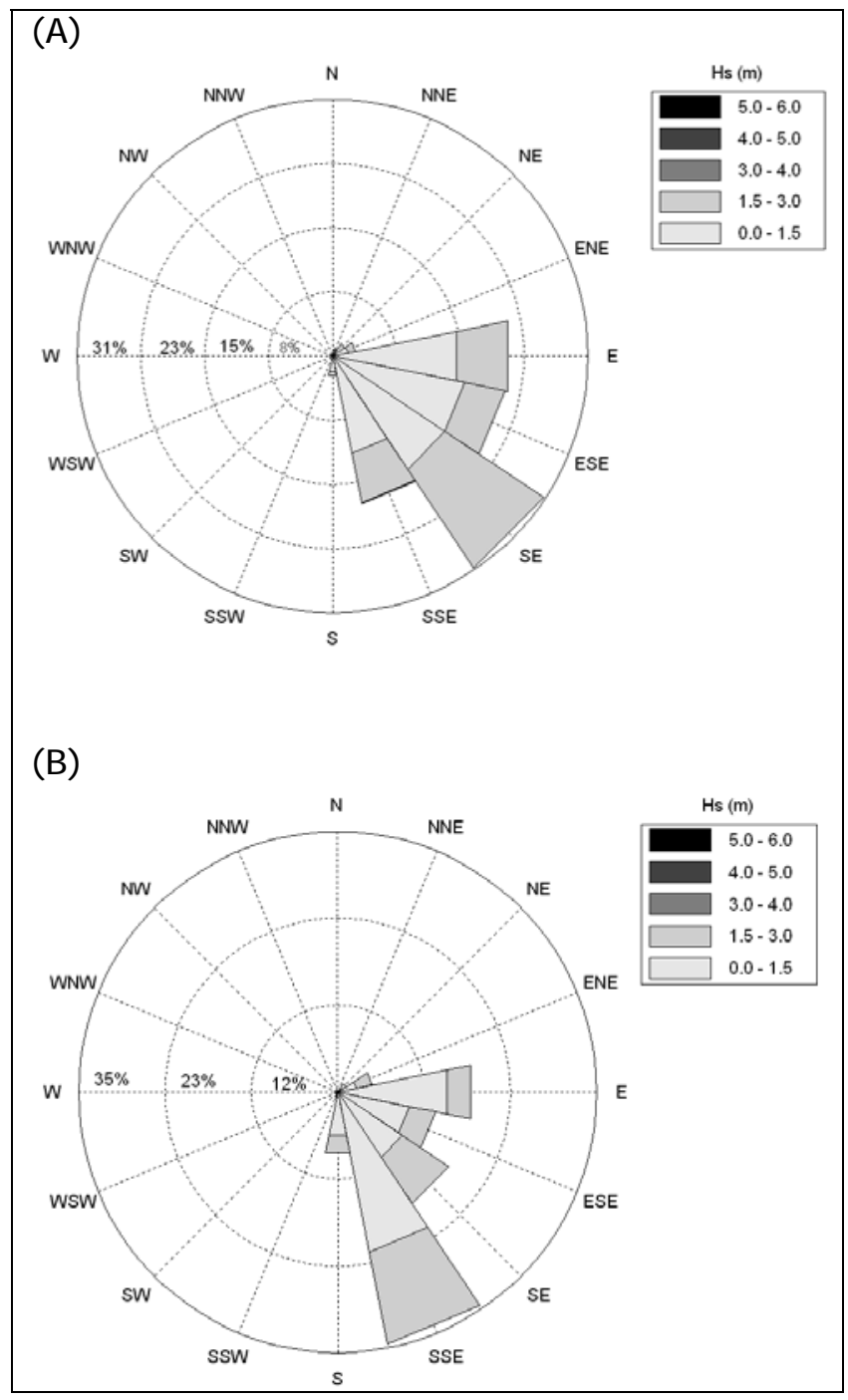

Figura 9 - Diagramas polares de freqüência da altura significativa e direção de propagação das ondas em Tramandaí, 2007. A) verão B) outono.

No outono em Tramandaí, os resultados indicaram alturas significativas de onda de até $4,0 \mathrm{~m}$ que se distribuíram entre as direções de ENE e $S$, com predominância para a direção de SSE, atingin- do as maiores freqüências os valores entre 1,0 e 2,0 m nesta direção, conforme figura 9B.

Em Rio Grande, no outono, as alturas significativas se distribuíram em todo o quadrante $\mathrm{SE}$, atingindo valores máximos de $5,0 \mathrm{~m}$ com um progressivo aumento de freqüência da direção $E$ para SSE, conforme figura 10B.

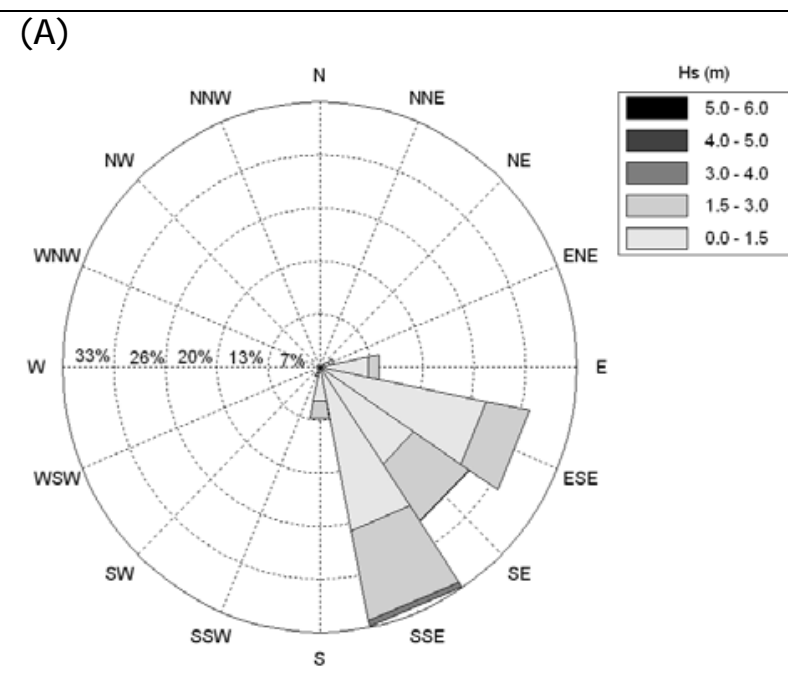

(B)

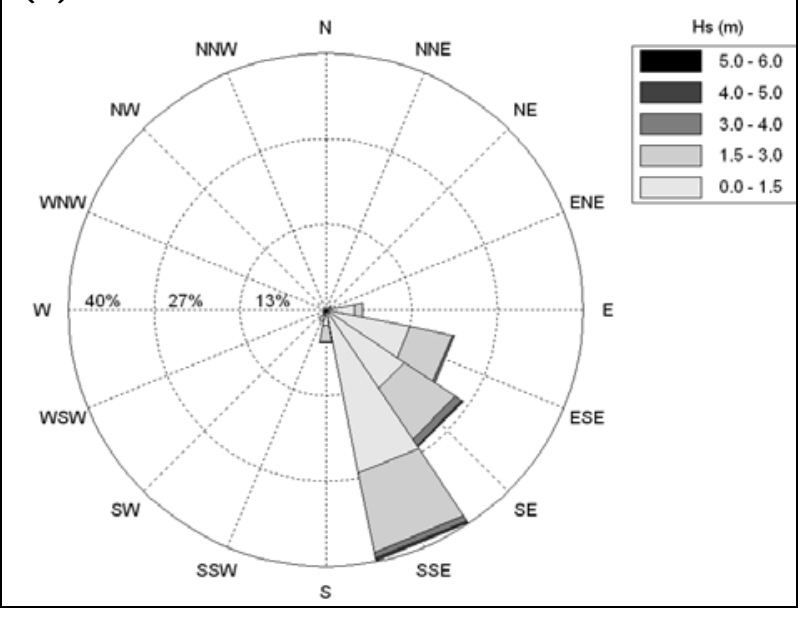

Figura 10 - Diagramas polares de freqüência da altura significativa e direção de propagação das ondas em Rio Grande (Strauch, 2001). A) verão B) outono.

Os períodos de pico no verão, tanto em Tramandaí como em Rio Grande, se distribuíram entre as direções de ENE e S. Em Tramandaí ocor- 
reram valores de até $15 \mathrm{~s}$ com predominância na direção de SE apresentando maior freqüência na faixa entre 9 e 12 s nesta direção (Figura 11A). Em Rio Grande os valores atingiram o máximo de $18 \mathrm{~s}$ com predominância na direção de SSE, apresentando maior freqüência na faixa entre 9 e $12 \mathrm{~s}$ nesta direção (Figura 12A).

No outono, em Tramandaí, os períodos de pico se distribuíram entre as mesmas direções observadas no verão, entretanto atingiram valores de até $19 \mathrm{~s}$ com predominância na direção de SSE, e apresentando maiores freqüência na faixa de 9 e 12 snesta direção (Figura 11B).

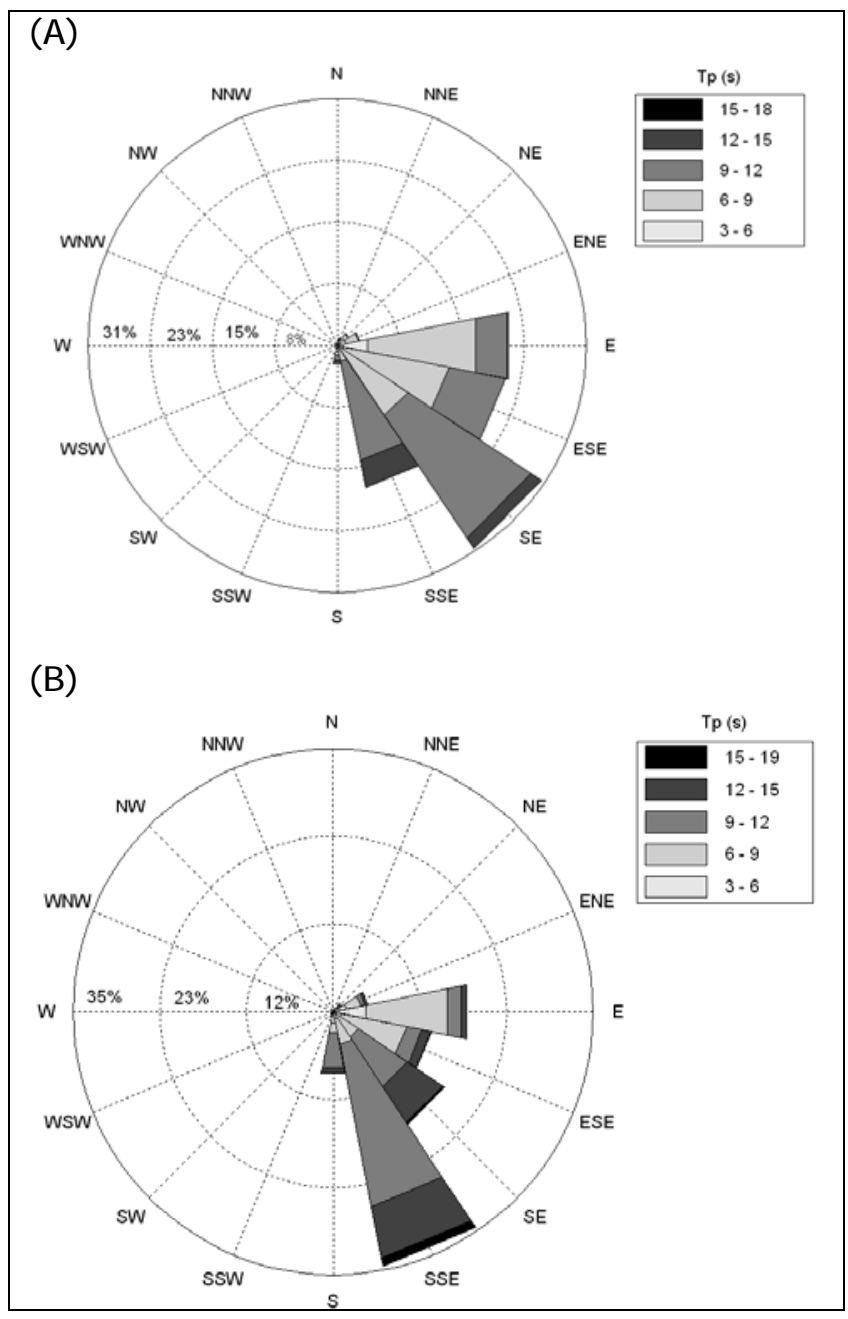

Figura 11 - Diagramas polares de período de pico e direção de propagação das ondas em Tramandaí, 2007. A) verão B) outono.

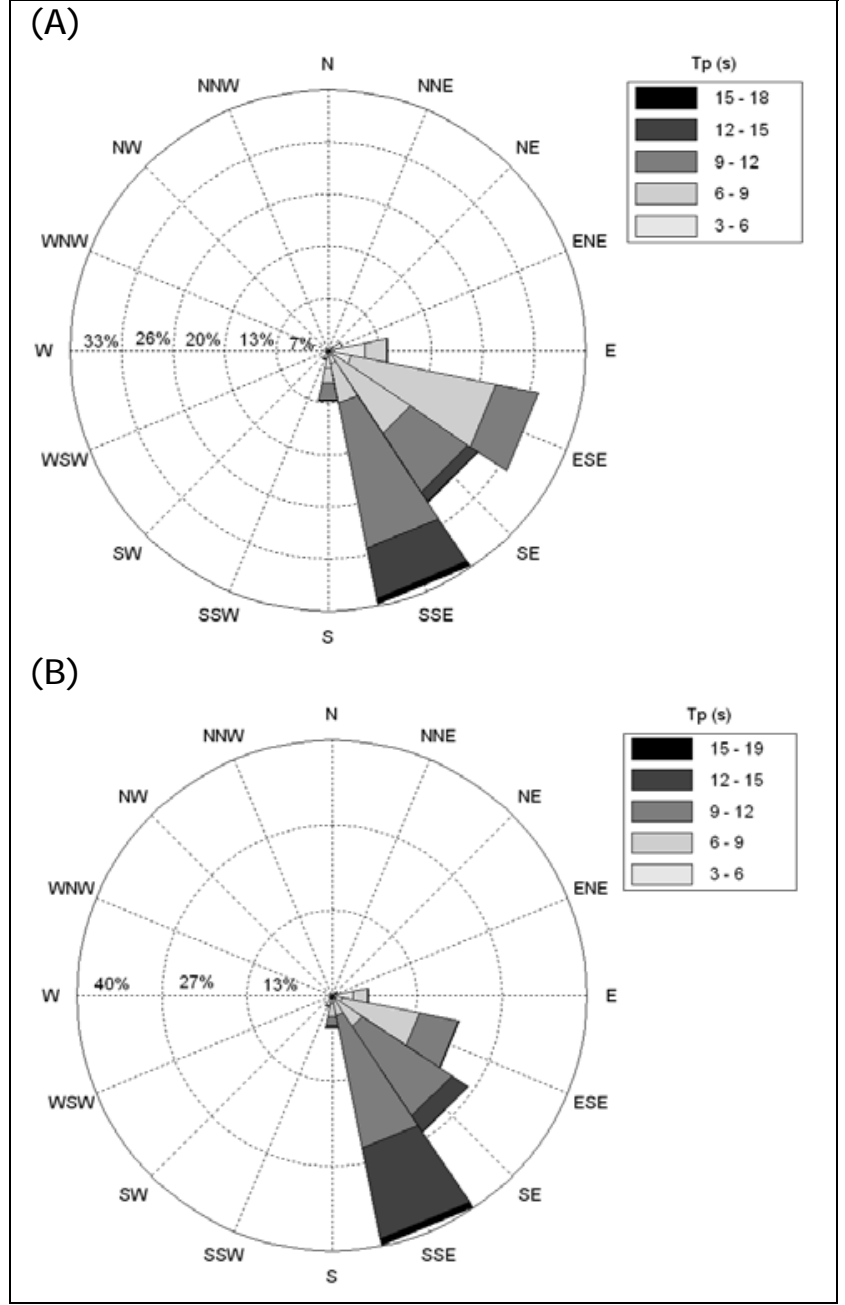

Figura 12 - Diagramas polares de período de pico e direção de propagação das ondas em Rio Grande, 2001. A) verão $B$ ) outono.

No outono, em Rio Grande, o período de pico ocorreu na faixa entre 9 e $12 \mathrm{~s}$. Os valores se distribuíram entre as direções de $\mathrm{E}$ e $\mathrm{S}$, atingindo o máximo de $19 \mathrm{~s}$ com a ocorrência aumentando de ESE para SSE, e predominância na direção de SSE (Figura 12B).

No outono, em Tramandaí, a maior freqüência de ocorrência de eventos mais energéticos ocorre na direção de SSE, enquanto que no verão estes eventos são de SE (Figuras 13A e 14A). Em Rio Grande, os eventos mais energéticos ocorrem tanto no verão quanto no outono, com predominância ma direção de SSE (Figuras 13B e 14B). 


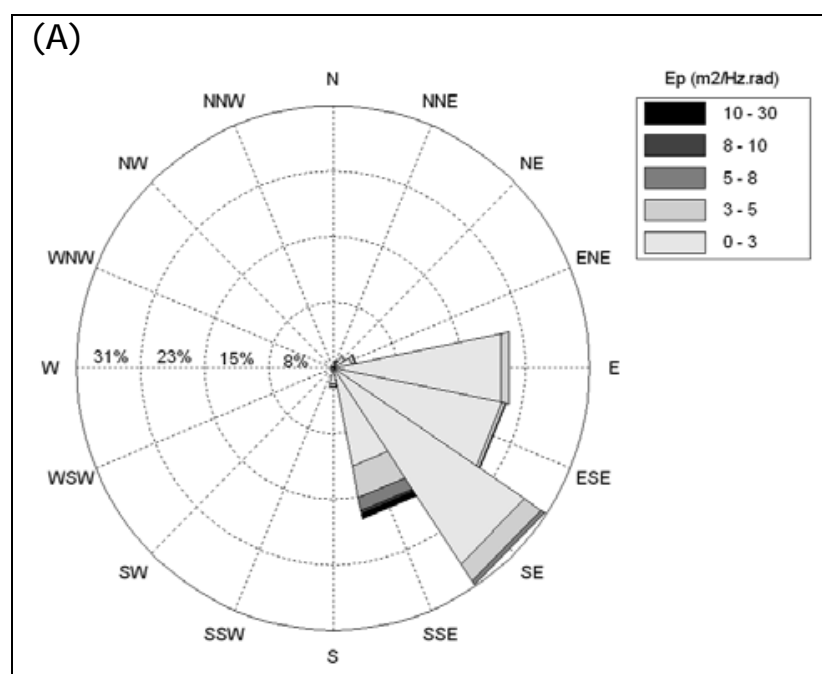

(B)

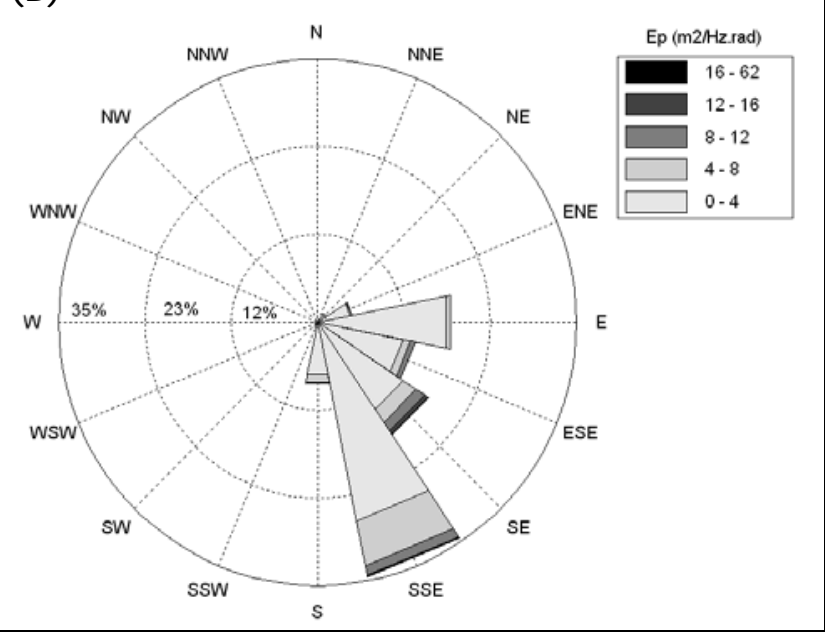

Figura 13 - Diagramas polares de energia de pico e direção de propagação das ondas em Tramandaí, 2007. A) verão B) outono.

\section{CONCLUSÕES}

Os dados apresentados neste trabalho foram analisados seguindo um procedimento padrão e os resultados discutidos em termos comparativos, com o objetivo de estabelecer a variabilidade espacial do clima de ondas ao longo da costa do Rio Grande do Sul. As análises envolvendo a altura, período e energia de pico das ondas, no verão e no outono permitem concluir sobre a existência de grande similaridade entre o comportamento do clima de ondas em Rio Grande e Tramandaí.
De modo geral as alturas, períodos e energia apresentam um progressivo aumento com a passagem da direção de propagação das ondas de Leste para Sul, atingindo os maiores valores na direção SSE e predominância para esta direção.

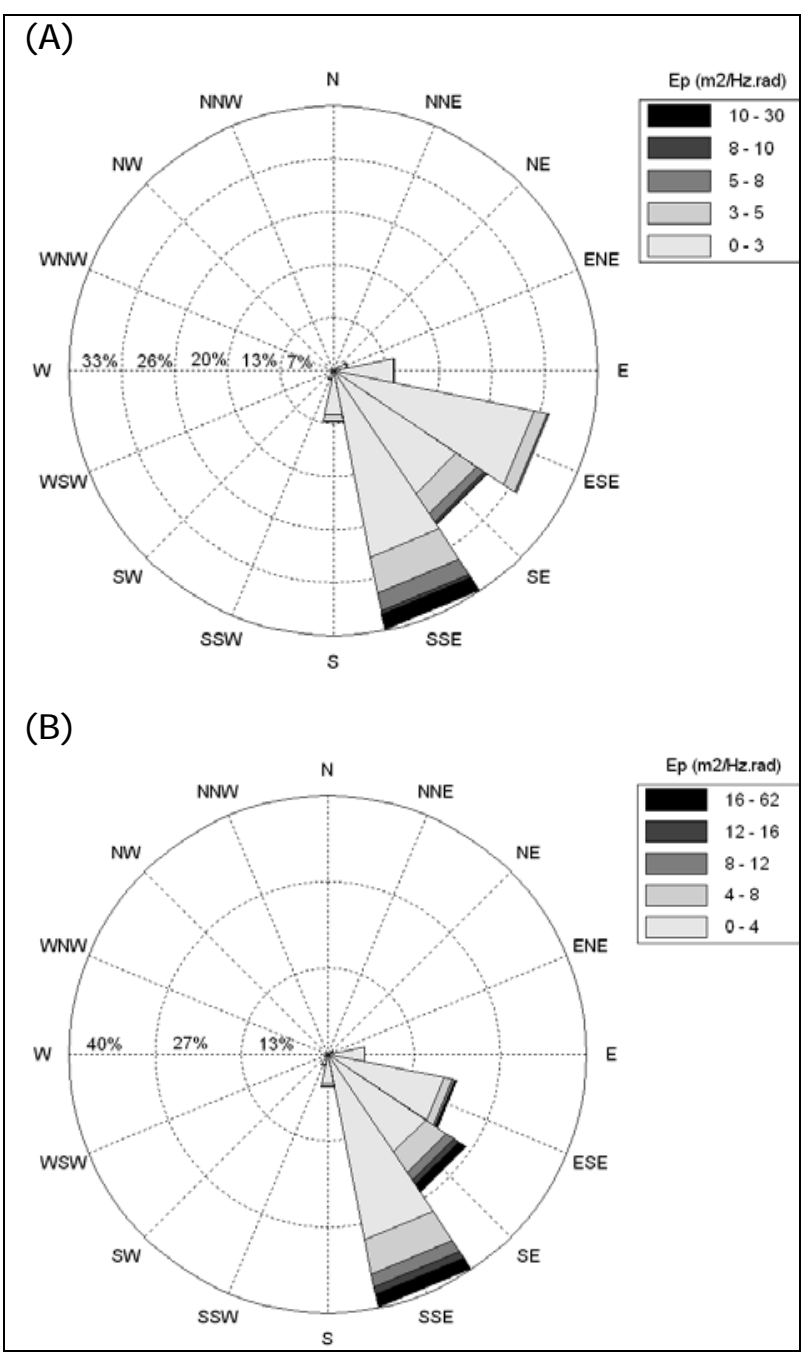

Figura 14 - Diagramas polares de energia de pico e direção de propagação das ondas em Rio Grande, 2001. A) verão B) outono.

Os regimes ondulatórios, correspondentes as vagas e ondulações, estão presentes nas duas estações do ano analisadas em Tramandaí e em Rio Grande. Entretanto, maiores concentrações de vagas são observadas nas direções entre E e ESE no verão, com uma predominância de E em Tramandaí e ESE em Rio Grande, enquanto que as ondulações ocor- 
rem com maior freqüência na direção SSE nos dois locais estudados.

Para as duas estações estudadas é possível afirmar que não existem diferenças significativas no clima de ondas, do mesmo modo como foi concluído por Wainer (1963).

\section{REFERÊNCIAS}

ALMEIDA, L.E.S.B.; ROSAURO, N.L.; TOLDO Jr., E.E. \& GRUBER, N.L.S. 1999. Avaliação da profundidade de fechamento para o litoral norte do Rio Grande do Sul. XIII Simpósio Brasileiro de Recursos Hidricos. Belo Horizonte, MG. Anais. ABRH, CD, 8 p.

ALMEIDA, L.E.S.B.; TOLDO E.E. 1997. Relatório Técnico - Projeto Estudos Ambientais em Áreas Costeiras e Oceânicas na Região Sul do País - Região de Osório, RS. Porto Alegre (RS) IPH/UFRGS.

INPH, INSTITUTO DE PESQUISAS HIDROVIÁRIAS. 1995. Relatório técnico final- Recuperação do Molhe Leste, Porto de Rio Grande, RS.

KING, C. A. M. 1972. Beaches and coasts. London: Edwards Arnold, 573p.

MACHADO, D. M.; STRAUCH, J. C. Previsão de Eventos Extremos para o Regime de Ondas na Região do Porto de Rio Grande. 2001. XIV Simpósio Brasileiro de Recursos Hídricos. Aracajú, SE.

STRAUCH, J. C. 1997. Monitoramento de Ondas em Rio Grande. XII Simpósio Brasileiro de Recursos Hídricos. Vitória, ES, v. 4, p. 385-391.

STRAUCH, J. C. 2001. Caracterização do Estado do Mar em Rio Grande - XIV Simpósio Brasileiro de Recursos Hidricos. Aracajú, SE.

STRAUCH, J.C.; TOLDO, E.E.; ALMEIDA, L.E. 2007. Monitoramento do clima de ondas em Tramandaí, VII Simpósio sobre Ondas, Marés, Engenharia Oceânica e Oceanografia por Satélite. Instituto de Pesquisas do Mar Almirante Paulo Moreira, Arraial do Cabo, RJ.

TOLDO JR., E. E.; ALMEIDA, L. E. S. B.; NICOLODI, J. L.; ABSALONSEN, L.; GRUBER, N. L. S. O. 2006. Controle da Deriva Litorânea no Desenvolvimento do Campo de Dunas e da Antepraia no Litoral Médio do Rio Grande do Sul. Pesquisas, v. 33, p. 35-42.

TOMAZELLI, L. J.; WILLWOCK, J.A. 1992. Considerações sobre o Ambiente Praial e a Deriva Litorânea de Sedimentos ao longo do Litoral Norte do RS. Pesquisas, v. 19, n. 1, p. 3-12.

WAINER, I. J. 1963. Relatório Técnico - Análise e Previsão das Alturas de Onda em Tramandaí. UFRGS, Instituto de Pesquisas Hidráulicas, IPH. Porto Alegre. $30 \mathrm{p}$.
The Pattern of Summer and Autumn Waves on the South and North Coast of Rio Grande do Sul

\section{ABST RACT}

Data series were analyzed to compare the ocean wavefield between the south and north coast of Rio Grande do Sul. The series were acquired using the Datawell wave rider directional on dograph anchored in O ctober 1996 near the mouth of Patos Lagoon in Rio Grande, and in N ovember 2006 at T ramandai beach, both at a depth of $17 \mathrm{~m}$. In this study the data measured are presented, involving significant height, significant period, energy and peak direction of the waves recorded. The results indicate a great similarity between the autumn and summer wave regime behavior for these two sites. The significant heights in summer, at Tramandaí and Rio Grande, were distributed with proportional values between 1.5 and 3.0 m from ESE to SSE, predominantly in the SE direction at Tramandaí, and SSE at Rio Grande. In autumn at Tramandaí, the results indicated significant height with a predominance of the SSE direction, the highest frequencies reaching values between 1.0 and $2.0 \mathrm{~m}$. At Rio Grande the significant heights occur in the SE quadrant, reaching maximum values of $5.0 \mathrm{~m}$ with a progressively increasing frequency from $E$ to SSE.

Keywords: ocean waves; wave pattern. 